\title{
Primjena spektroskopije NMR u analizi biodizela
}

\section{J. Parlov Vuković*}

INA - Industrija nafte d. d., SD Rafinerija i marketing, Služba za razvoj

proizvoda, Centralni ispitni laboratorij, Lovinčićeva 4, 10002 Zagreb

\section{$\|$ Sažetak}

U ovome preglednom radu opisane su najznačajnije i najčešće primjenjivane jednodimenzijske i dvodimenzijske tehnike NMR u analizi biodizela. Biodizel je ekološki prihvatljivo alternativno gorivo koje se sastoji od zasićenih i nezasićenih metilnih estera masnih kiselina. Budući da analiza kemijskog sastava i proučavanje svojstava biodizela i ostalih biogoriva analitičarima predstavlja izazov, sve više se razvijaju nove i učinkovitije analitičke metode. Spektroskopija NMR jedna je od takvih metoda koja može dati niz informacija o sastavu i strukturi biodizela. Nadalje, analiza spektara NMR pruža vrijedne podatke i o sirovinama iz kojih nastaje biodizel te o procesu esterifikacije. Isto tako primjenom tehnika ${ }^{1} \mathrm{H} \mathrm{i}{ }^{13} \mathrm{C}$ NMR može se odrediti sastav aditiva koji se dodaju za sprječavanje rasta mikroorganizama i sastav smjese acetilglicerola i sličnih nusproizvoda sinteze biodizela. $U$ tu svrhu se osim spektara ${ }^{1} \mathrm{H} \mathrm{i}^{13} \mathrm{C}$ analiziraju i spektri ${ }^{31} \mathrm{P}$. $\mathrm{U}$ radu su dani karakteristični spektri biodizela, dizela, biljnog ulja tretiranog vodikom te reprezentativan spektar jednog od uzoraka biocida snimljeni u Laboratoriju za spektroskopiju NMR u INA d. d.

$\|$ Ključne riječi

Spektroskopija NMR, biodizel, metilni esteri masnih kiselina, biljno ulje tretirano vodikom

\section{Uvod}

Biogorivo je svako kruto, tekuće ili plinsko gorivo proizvedeno direktno iz biomase. Biogoriva se svrstavaju u generacije za koje nema precizne tehničke definicije. ${ }^{1}$ Prva generacija goriva proizvodi se iz žitarica s visokim sadržajem škroba ili šećera (biometanol, biobutanol) te iz uljarica (biodizel). Druga generacija biogoriva dobiva se iz iskorištenih ulja iz domaćinstva te iz lignoceluloze (dio biomase koja potječe od ostatka proizvodnje žitarica te iz biorazgradljivog dijela otpada ili biljaka i stabala ciljano uzgojenih radi proizvodnje energije). U treću generaciju goriva ubrajaju se biogoriva dobivena iz mikroalgi i makroalgi.

Biodizel je ekološki prihvatljivo alternativno gorivo za dizelske motore s fizikalnim svojstvima vrlo sličnim mineral- nim gorivima. ${ }^{2-4}$ Upotreba biodizela ne zahtijeva nikakvu modifikaciju dizelskog motora. Biodizel (engl. fatty acid methyl ester, FAME) se sastoji od zasićenih i nezasićenih alkilnih estera masnih kiselina, a pojedinačna svojstva različitih masnih estera utječu na sveukupna svojstva biodizelskog goriva. Strukturne značajke molekula masnih estera koje utječu na fizikalna i kemijska svojstva goriva su duljina lanca, stupanj nezasićenosti i grananje. U industrijskoj proizvodnji biodizelskoga goriva primjenjuju se različite tehnologije, a najviše je razvijen način proizvodnje pomoću procesa transesterifikacije s alkalnim katalizatorom (slika 1), čime se ostvaruju visoki stupnjevi konverzije masti, odnosno ulja u odgovarajuće estere u kratkom vremenu.

Zamjenom glicerola s metanolom od jedne molekule triglicerida nastaju tri molekule monoalkilnih estera.<smiles>[R]OC([R])([R])O[R]</smiles>

Slika 1 - Transesterifikacija masnih kiselina

Fig. 1 - Transesterification of fatty acid

\footnotetext{
* Dr. sc. Jelena Parlov Vuković

e-mail: jelena.parlov-vukovic@ina.hr
} 
Velika viskoznost prirodnih ulja i masti glavni je razlog zašto ih ne možemo izravno upotrebljavati za rad motora. ${ }^{5}$ Procesom transesterifikacije viskoznost se približava vrijednosti viskoznosti mineralnih goriva. Oksidacijom biodizela može doći do nastajanja polimernih komponenata visoke molekulske mase, što povećava viskoznost.

\section{Spektroskopija NMR u analizi biodizela}

\section{Praćenje procesa transesterifikacije}

Zbog ograničenja najvažnijih energetskih resursa, zahtjevima za primjenom tehnologija pogodnih za okolišs, zdravlje ljudi i sigurnost te uvođenja alternativnih goriva u cestovni prijevoz, zadnjih godina zabilježen je značajan napredak u razvoju analitičkih tehnika i metoda za analizu biogoriva.

Spektroskopija nuklearne magnetske rezonancije (NMR) pokazala se prikladnom za praćenje procesa transesterifikacije. ${ }^{6-9}$ Objavljeno je više radova u kojima se pomoću analize spektara ${ }^{1} \mathrm{H} \mathrm{i}{ }^{13} \mathrm{C}$ NMR određivao stupanj konverzije $(\mathrm{C})$ biljnog ulja u metilne estere. ${ }^{3,8,10} \mathrm{U}$ spektrima ${ }^{1} \mathrm{H}$ NMR dizelskih goriva jasno se vidi prisutnost metilnih estera (slika 2a i 2b).

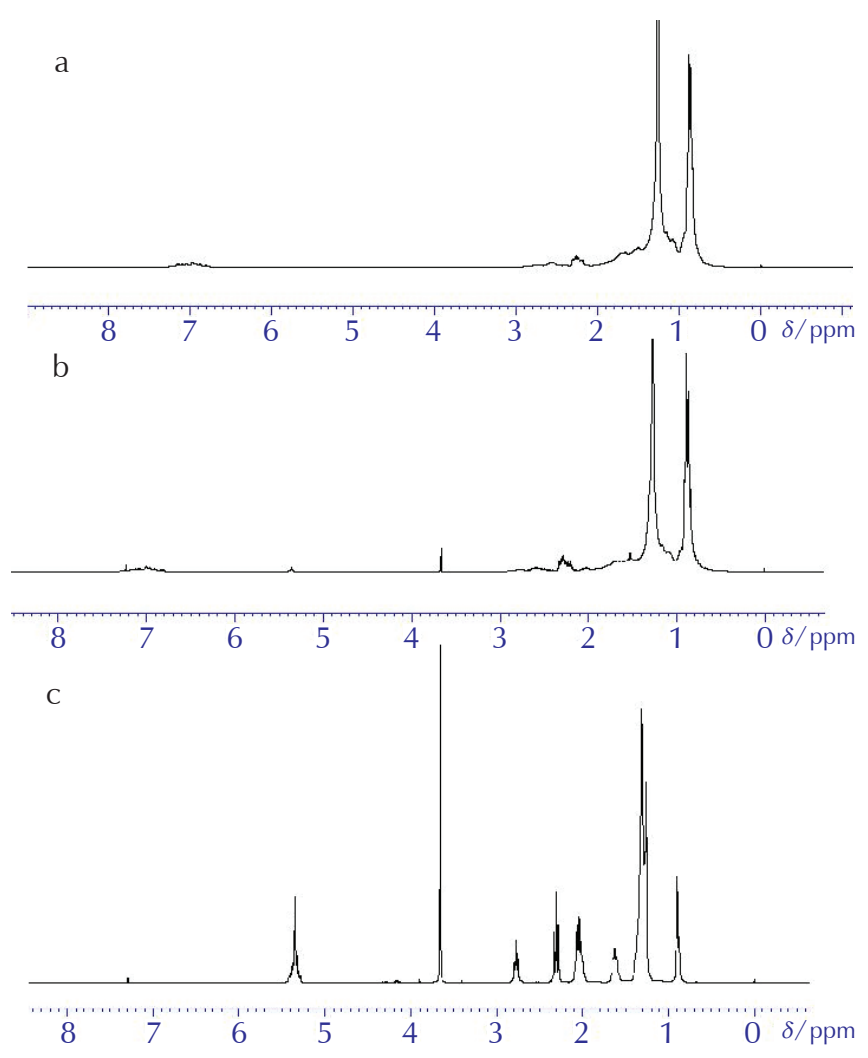

Slika 2 - Tipičan spektar ${ }^{1} \mathrm{H}$ NMR dizelskog goriva (a), spektar ${ }^{1} \mathrm{H}$ NMR dizelskog goriva s dodanim metilnim esterima (b) i spektar metilnih estera masnih kiselina (c)

Fig. 2 - A typical ${ }^{1} \mathrm{H}$ NMR spectrum of diesel fuel (a), ${ }^{1} \mathrm{H}$ NMR spectrum of a diesel fuel with fatty acid methyl esters (b) and ${ }^{1} \mathrm{H}$ NMR spectrum of fatty acid methyl esters (c)
Stupanj konverzije određuje se iz odnosa signala koji pripadaju metilnim esterima $(3,6-3,7 \mathrm{ppm})$ i signala za protone skupina $\mathrm{CH}_{2}(2,3 \mathrm{ppm})$. Skupina autora je istraživala mogućnost spektroskopije ${ }^{1} \mathrm{H}$ NMR u određivanju stupnja miješanja metilnih biodizela u dizelskim gorivima različitog porijekla. ${ }^{2}$ Dobiveni rezultati pokazali su da na određivanje sadržaja biodizela u dizelu spektroskopijom ${ }^{1} \mathrm{H}$ NMR ne utječe niti vrsta biodizela niti vrsta dizela te da je tehnika posebno dobra za takva istraživanja. Osim u praćenju procesa konverzije spektroskopija NMR primjenjuje se u određivanju sadržaja masnih kiselina te određivanju glicerola, monoglicerida i diglicerida. ${ }^{10-13}$

Na slici 2c prikazan je tipičan spektar ${ }^{1} \mathrm{H}$ NMR metilnih estera masnih kiselina.

Casas i sur. predložili su metodu za brzo kvantitativno određivanje sastava smjese acetilglicerola, kao nusproizvoda sinteze biodizela, pomoću spektroskopije ${ }^{13} \mathrm{C}$ NMR. ${ }^{14}$ Pri tome su analizom spektara ${ }^{1} \mathrm{H}$ i ${ }^{13} \mathrm{P}$ NMR identificirali i kvantificirali uzorke monoacetina i diacetina, a za točnu asignaciju signala primijenili su dvodimenzijsku tehniku NMR ${ }^{1} \mathrm{H}_{-13}{ }^{13} \mathrm{C}$ gHSQC (Gradient Heteronuclear Single Quantum Coherence).

\section{Praćenje oksidacije biodizela te određivanje profila masnih kiselina}

Poznato je da prednosti biodizela u odnosu na mineralna dizelska goriva uključuju smanjenje većine ispušnih plinova (iznimka su dušikovi oksidi) i poboljšanje biorazgradivosti. Sirovine za biodizel su obnovljive, pa znatno doprinose smanjenju globalnog zatopljenja zbog zatvorenog kruga ugljikova dioksida. Više plamište biodizela u odnosu na petrodizel omogućava sigurniji rad i skladištenje goriva. Nadalje, biodizel ima izvorno porijeklo, što donosi nova radna mjesta i doprinosi lokalnoj ekonomiji. Međutim, neka svojstva biodizela imaju nedostatke u odnosu na mineralna goriva. Biodizel pri niskim temperaturama (ispod točke zamućenja) formira nakupine parafina koje mogu dovesti do začepljenja filtra na motorima. Biodizeli imaju višu temperaturu tečenja (engl. pour point) i stinjavanja (engl. gelling point) od petrodizela. Proučavanje kemijskog sastava i svojstava biodizela već godinama analitičarima predstavlja velik izazov. $U$ novije vrijeme povećanje upotrebe biodizela suočava se s nekoliko tehničkih izazova, kao što su smanjenje sadržaja dušikovih oksida $\left(\mathrm{NO}_{x}\right)$ ispušnih plinova kao i poboljšanje oksidacijske stabilnosti. Više autora je istraživalo utjecaj svjetla, povećanja temperature, metala i vrste spremnika na kvalitetu biodizelskog goriva. ${ }^{5}$ Komercijalni biodizel prilikom prijevoza i skladištenja može biti izložen povećanim temperaturama, osobito u toplim vremenskim prilikama. To dovodi do ubrzane oksidacije goriva. Procesom oksidacije biodizela dolazi do promjene sastava te kemijskih i fizikalnih svojstava goriva. Ovakve promjene ne odnose se samo na kvalitetu biodiezela već i na materijal koji je u kontaktu s njim. Oksidacijom biodizela mogu nastati masne kiseline s kraćim lancima i aldehidi, ali može doći i do polimerizacije, gdje nastaju molekule (produkti) veće molekulske mase. Autoksidacija lipida je proces koji se proučava u sklopu kemijkkih i bioloških istraživanja. ${ }^{5}$ Ona se odvija u tri stupnja: inicijacija, propagacija i terminacija. 


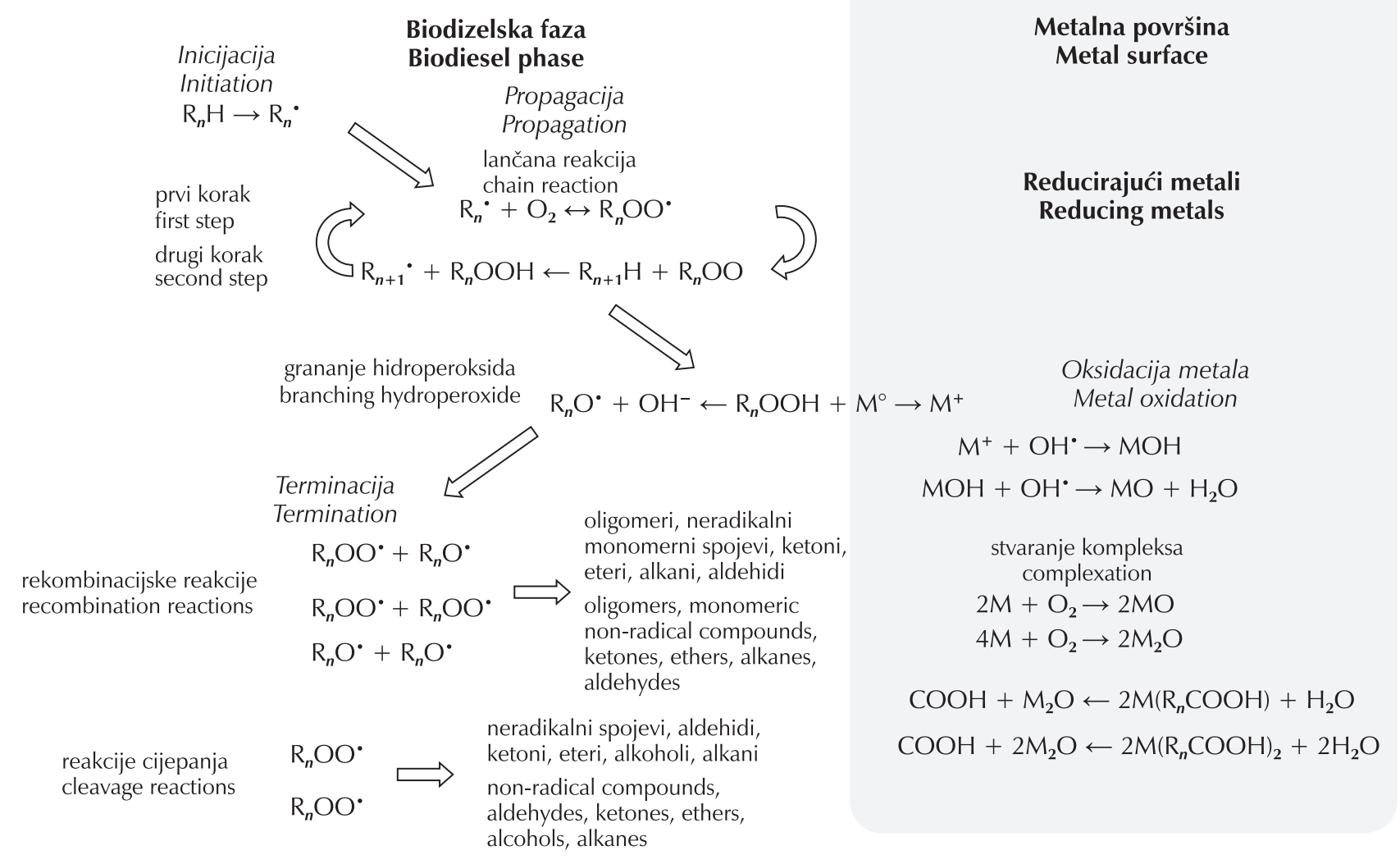

Slika 3 - Proces oksidacije lipida

Fig. 3 - Oxidation of lipids

U stupnju inicijacije slobodni radikal napada lipid, odvaja alilni vodik te stvara alilni radikal $\left(\mathrm{R}_{n}{ }^{\circ}\right)$. U ovom stupnju nastaje malo produkata oksidacije. Stupanj propagacije odvija se u dva koraka. $U$ prvom koraku alilni radikal $\left(\mathrm{R}_{n}{ }^{\circ}\right)$ reagira s molekulom kisika zbog čega nastaje peroksi radikal $\left(\mathrm{R}_{n} \mathrm{OO}\right)^{*}$. U drugom koraku peroksi radikal uklanja drugi alilni vodik te nastaju alilni hidroperoksid $\left(\mathrm{R}_{n} \mathrm{OOH}\right) \mathrm{i}$ novi alilni radikal $\left(R_{n+1}\right)$ koji ponovno reagira s molekulom kisika, što dovodi do lančane reakcije. Za vrijeme terminacije uklanjaju se radikali nastali u prethodna dva stupnja.

Produkti prikazanih reakcija (slika 3) su alkoholi, ketoni, eteri, alkani, organske kiseline, aldehidi, oligomeri i drugi.

U svrhu praćenja oksidacije biodizela stalno se razvijaju nove i sve sofisticiranije analitičke metode i tehnike. Prijašnja istraživanja vezana za praćenje oksidacije biodizela uključivala su i određivanje kiselinskog broja, gustoće i kinematičke viskoznosti. Knothe je razvio pristup za analizu karakteristika biodizela prije i poslije oksidacije pomoću ${ }^{1} \mathrm{H}$ NMR spektroskopije. ${ }^{7} \mathrm{U}$ otvorenim posudama različite veličine zagrijane su jednake količine biodizela te su izložene djelovanju zraka. Rezultati za kiselinski broj i kinematičku viskoznost dobiveni analizom ${ }^{1} \mathrm{H}$ spektara NMR uspoređeni su s rezultatima dobivenim gel-propusnom kromatografijom i elektronskom UV-VIS spektroskopijom. ${ }^{15}$ Pokazalo se da je spektroskopija ${ }^{1} \mathrm{H}$ NMR vrlo pogodna tehnika za određivanje profila masnih kiselina (slika 2c). Udjel nezasićenih masnih kiselina biljnog ulja sa strukturama $18: 1,18: 2$ i $18: 3$ te zasićenih masnih ki- selina može biti izračunan prema sljedećim jednadžbama kao što je navedeno za određivanje udjela masnih kiselina $18: 1\left(A_{18: 1}\right):$

$$
A_{18: 1}=I_{\text {eksp,metil, 18:3 }} /\left(I_{\text {eksp,metil,18:3 }}+I_{\text {eksp, metil,ostalo }}\right),
$$

gdje je $I_{\text {eksp,metil, } 18: 3}$ eksperimentalna vrijednost integrala protona terminalne skupine $\mathrm{CH}_{3}$ linoleinske kiseline, a

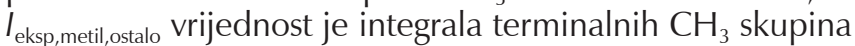
svih ostalih masnih kiselina.

Udjel masne kiseline 18:2( $\left.A_{18: 2}\right)$ može se odrediti pomoću jednadžbe:

$$
A_{18: 2}=1 / 2\left(l_{\text {eksp,bisalini }}-4 A_{18: 3}\right),
$$

gdje je $I_{\text {eksp,bisalini }}$ eksperimentalna vrijednost integrala za bisalilne protone.

Udjel mononezasićenih masnih kiselina $\left(A_{18: 1}\right)$ je dan jednadžbom:

$$
A_{18: 1}=\left(I_{\text {eksp,alilini }} / 4\right)-A_{18: 2}-A_{18: 3},
$$

gdje je $I_{\text {eksp,alini }}$ eksperimentalna vrijednost integrala za alilne protone.

Udjel zasićenih masnih kiselina može biti izračunan oduzimanjem udjela nezasićenih masnih kiselina od $100 \%$.

Isti autor u svojim je istraživanjima svojstava biodizela nakon oksidacije zaključio da se kiselinski broj i peroksidni 
broj povećavaju, a sadržaj metilnih estera smanjuje nakon procesa oksidacije. $^{2}$

Iz literature je vidljivo da se spektroskopija ${ }^{13} \mathrm{C} N \mathrm{NR}$, osim u analizi mineralnih goriva, ${ }^{16-22}$ sve više primjenjuje i u analizi masnih kiselina i estera masnih kiselina. ${ }^{14,23-24}$

Na slici 4 prikazan je tipičan spektar ${ }^{13} \mathrm{C}$ NMR metilnih estera masnih kiselina.

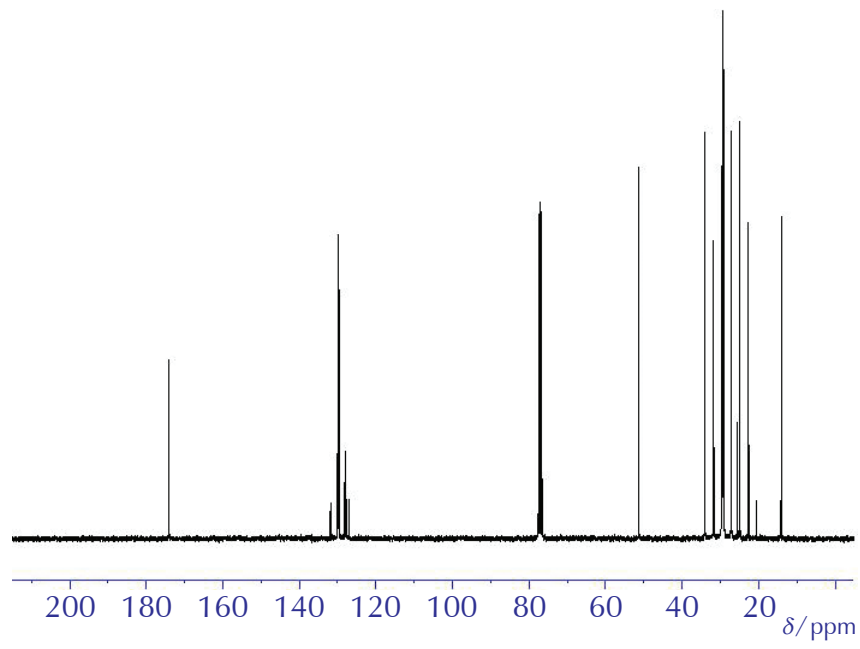

Slika 4 - Spektar ${ }^{13} \mathrm{C}$ NMR dizelskog goriva

Fig. $4-{ }^{13} \mathrm{C}$ NMR spectrum of the diesel fuel sample

Stabilnost biodizela za vrijeme skladištenja istraživalo je više autora. Praćene su promjene karakteristika biodizela skladištenog kroz dulje razdoblje uz prisutnost različitih materijala te pod utjecajem i bez utjecaja svjetlosti i kisika. U takvim uvjetima došlo je do promjena jodnog, peroksidnog i kiselinskog broja, viskoznosti, količine metilnih estera, oksidacijske stabilnosti i količine netopivog materijala. ${ }^{5}$

\section{Određivanje jodnog broja}

Važno svojstvo biodizela je ukupna količina nezasićenih masnih kiselina u uljima ili mastima koja se prikazuje jodnim brojem. Određivanje jodnog broja korisno je za prevenciju problema koji se javljaju na motoru pri njegovim visokim vrijednostima. Može doći do nastajanja polimera i taloga na mlaznicama, klipnim prstenima i utorima. Također se mogu pojaviti produkti raspadanja biogoriva te smanjiti mazivost. Međunarodne i lokalne organizacije za normizaciju razvile su i predložile više instrumentno-analitičkih metoda za određivanje jodnog broja. ${ }^{25} \mathrm{U}$ posljednje vrijeme sve više se primjenjuje spektroskopija NMR u analizi biogoriva. Istraživanja obuhvaćaju i određivanje jodnog broja gdje se spektroskopija ${ }^{1} \mathrm{H}$ NMR pokazala kao pogodna metoda za tu namjenu. Tako je grupa autora primijenila analizu NMR za određivanje jodnog broja biljnih ulja i biodizela namiješanih u mineralna goriva. ${ }^{25}$ Analizirani su uzorci s dodatkom i bez dodatka unutarnjeg standarda 1,4-dioksana. Autori su za izračun uzeli u obzir samo dva područja spektra ${ }^{1} \mathrm{H}$ NMR, područje rezonancije dvostru- kih veza (olefinski vodik) i signale koji pripadaju 1,4-dioksanu. Tako dobiveni rezultati uspoređeni su s rezultatima dobivenim volumetrijskom standardnom metodom UNEEN 14111 za određivanje jodnog broja. Bolje slaganje s rezultatima dobivenim standardnom metodom postignuto je primjenom unutarnjeg standarda. Iz dobivenih rezultata vidjelo se da je metoda NMR brža i jednostavnija od standardne metode. Nadalje, moguća je i izravna identifikacija i kvantifikacija dvostrukih veza, a nije nužno prije analize poznavati približnu vrijednost jodnog broja analiziranog uzorka.

Reda $i$ sur. predložili su alternativnu metodu ${ }^{1} \mathrm{H}$ NMR za određivanje jodnog broja na uzorcima biodizela dobivenim transesterifikacijom iz biljnih ulja upotrebljavajući alkohol etanol. ${ }^{26}$

Igarashi $i$ sur. ${ }^{27}$ primijenili su spektroskopiju ${ }^{1} \mathrm{H}$ NMR za određivanje $\omega$-3 kiseline u ribljem ulju. Dobiveni rezultati dobro su se slagali s onima dobivenim plinskom kromatografijom.

\section{Utjecaj biodizela na metale}

Kao što je već ranije u ovom pregledu navedeno, dizelsko gorivo ima i neke nedostatke u odnosu na biodizel. Jedan od njih je veća sklonost koroziji koja može biti uzrokovana prisustvom slobodne vode ili slobodnih masnih kiselina u gorivu. Slobodne masne kiseline mogu se pojaviti zbog nepotpune transesterifikacije. Biodizel je u odnosu na mineralna goriva više sklon apsorpciji vode, jer esteri u biogorivima pokazuju neka higroskopna svojstva, koja znatno povećavaju sadržaj vode. Voda se kondenzira na površini metala te izaziva koroziju i propadanje materijala. Istraživanja u ovom području bila su uglavnom usmjerena na produkte korozije, a ne na reakcijske putove nastanka produkata. Praćene su promjene pod utjecajem različitih temperatura. ${ }^{5}$ Slitine i metali, kao što su bronca, bakar, olovo, kositar i cink mogu katalizirati oksidaciju biodizela zbog čega nastaju talozi. Aluminij i čelik su metali kompatibilni s biodizelom.

\section{Određivanje cetanskog broja}

Izbor sirovine obično je jedan od najvažnijih faktora koji utječu na sastav dizela, jer različite biljne i životinjske masti mogu sadržavati različite vrste masnih kiselina. Sastav biogoriva utječe na njegova svojstva. Vrlo važan pokazatelj kvalitete goriva je cetanski broj. Određivanje cetanskog broja je obično dugotrajan i skup postupak. Skupina autora razvila je pristup predviđanja vrijednosti cetanskog broja biogoriva pomoću strukturnih podataka dobivenih spektroskopijom ${ }^{1} \mathrm{H}$ NMR u kombinaciji sa statističkom metodom analize glavnih komponenata (engl. principal component analysis, PCA). ${ }^{28}$

Spektroskopija NMR se zbog velikog broja informacija koje daje o sastavu kompleksnih ugljikovodičnih smjesa posljednjih godina sve više primjenjuje u kombinaciji sa statističkim metodama, kao što su metoda najmanjih kvadrata (engl. partial least squares regression, PLSR), višestruka linearna regresija (engl. multiple linear regression, MLR) te 
umjetne neuronske mreže (engl. artificial neural networks, ANNs) za praćenje nekih procesa u naftnoj industriji te predviđanje svojstava goriva.

Prosječni strukturni parametri dobiveni spektroskopijom ${ }^{1} \mathrm{Hi}{ }^{13} \mathrm{C}$ NMR primijenjeni su za proučavanje utjecaja ugljikovodičnog sastava na svojstva avionskih, benzinskih, dizelskih i biodizelskih goriva. ${ }^{29-34}$

Kapur i sur. su upotrijebili metodu višestruke linearne regresije za postavljanje korelacije između fizikalno - kemijskih svojstava (gustoća, cetanski broj, cetanski indeks, viskoznost, sadržaj sumpora, točka paljenja i volumni postotak destiliranog do $350{ }^{\circ} \mathrm{C}$ ) komercijalnih dizelskih goriva i brojčanih vrijednosti integrala identificiranih skupina u spektru ${ }^{1} \mathrm{H}$ NMR. ${ }^{29}$

Nadalje, razvijen je model za predviđanje vrijednosti cetanskog broja dizelskih goriva pomoću strukturnih podataka dobivenih spektroskopijom ${ }^{1} \mathrm{H}$ NMR u kombinaciji sa statističkom metodom umjetnih neuronskih mreža. ${ }^{35}$ Slično tome istraživan je i utjecaj sastava dizelskih i avionskih goriva na njihova svojstva. ${ }^{36}$

\section{Analiza aditiva}

Za vrijeme skladištenja i transporta biodizela može doći do kontaminacije goriva mikroorganizmima koji mogu izazvati niz problema. Tako oni uzrokuju povećanje sadržaja vode, nastanka sedimenata i krutih čestica u gorivu. Mogu izazvati koroziju na unutarnjim zidovima spremnika te potaknuti razgradnju ugljikovodika. Neke vrste bakterija i plijesni stvaraju polimere koji začepljuju cjevovode, ventile, filtre i dijelove automatske opreme. Isto tako endotoksične bakterije potencijalno su patogene i mogu uzrokovati zdravstvene probleme. Klofutar i Golob proučavali su razvoj mikroorganizama u biodizelu i mineralnom gorivu $\mathrm{s}$ dodanim biodizelom pod definiranim uvjetima. ${ }^{37}$

Za sprječavanje rasta mikroorganizama u biodizelu dodaju se biocidi (slike 5 i 6).

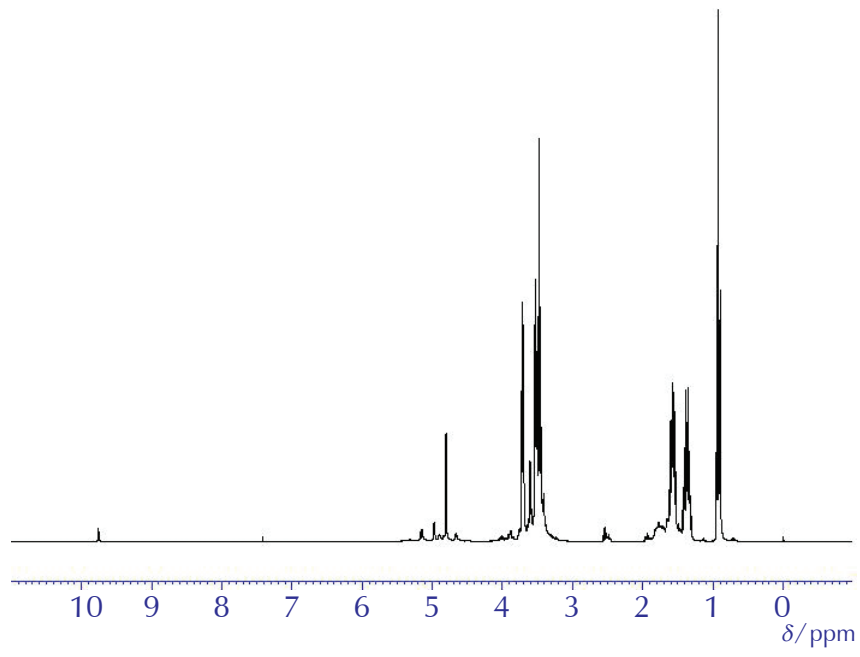

Slika 5 - Spektar ${ }^{1} \mathrm{H}$ NMR biocida

Fig. $5-{ }^{1} \mathrm{H}$ NMR spectrum of biocide

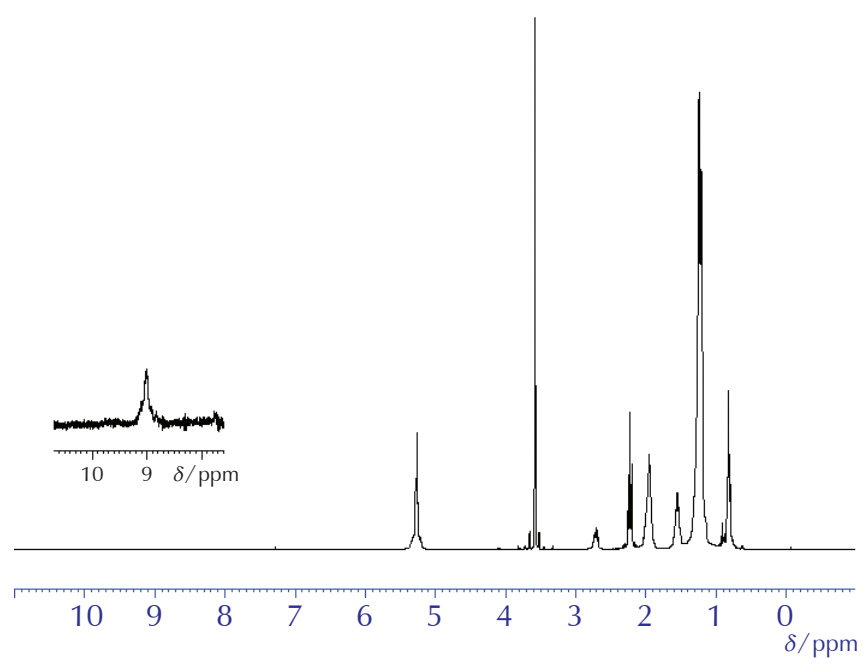

Slika 6 - Spektar ${ }^{1} \mathrm{H}$ NMR estera masnih kiselina s dodanim biocidom

Fig. $6-{ }^{1} \mathrm{H}$ NMR spectrum of fatty acid methyl esters with biocide

Pri proizvodnji i distribuciji goriva veliku ulogu imaju aditivi kojima se poboljšavaju njihova fizikalna i kemijska svojstva. ${ }^{38}$ Aditivi imaju široku primjenu u naftnoj industriji. Primjena aditiva započinje već u procesu izrade bušotina. Primjenjuju se pri transportu i preradi nafte te se dodaju naftnim proizvodima. Oni mogu već u vrlo malim količinama od svega nekoliko $\mathrm{mg} / \mathrm{kg}$ izmijeniti svojstva goriva. Spektroskopija ${ }^{1} \mathrm{H} \mathrm{i}{ }^{13} \mathrm{C}$ NMR visokog razlučivanja primjenjivala se za određivanje strukture, sastava, konformacije, grananja te za određivanje prosječne molekulske mase topivih polimernih aditiva. ${ }^{39-46}$

\section{Biljna ulja tretirana vodikom}

Zbog donesenih zakona i ograničenja vezanih uz uporabu obnovljivih izvora energije, posljednjih godina zabilježen je značajan razvoj u proizvodnji naprednih goriva, odnosno goriva druge i treće generacije koja se proizvode iz sirovina koje se izravno ne natječu s usjevima za potrebe prehrane. Biljna ulja tretirana vodikom (engl. hydrotreated vegetable oils, HVO) već su našla svoju komercijalnu primjenu u Finskoj u rafineriji Neste Oil. HVO je parafinsko dizelsko gorivo (slika 7) koje se proizvodi iz različitih vrsta biljnih ulja i životinjskih masti.

U procesu proizvodnje HVO-a vodik zamjenjuje kisik iz triglicerida. HVO ima niz prednosti u odnosu na dizel i FAME. Ne sadrži aromatske ugljikovodike i sumpor te ima visoku vrijednost cetanskog broja. Ima slična svojstva fosilnim gorivima, pa se može namiješati neograničeno $u$ dizelsko gorivo. Kao gorivo može se upotrebljavati namiješano u dizel ili se može dodati zajedno s FAME-om u dizel poštujući propisanu proceduru. ${ }^{1,47} \cup$ svojim istraživanjima hidrokrekiranja (engl. hydrocracking) vakuumskih plinskih ulja i mješavina biljnih ulja Bezergianni i sur. primijenili su tehnike spektroskopije NMR. ${ }^{47}$ HVO se može i samostalno upotrijebiti za pogon nekih motora, kao što su npr. gradski autobusi. 


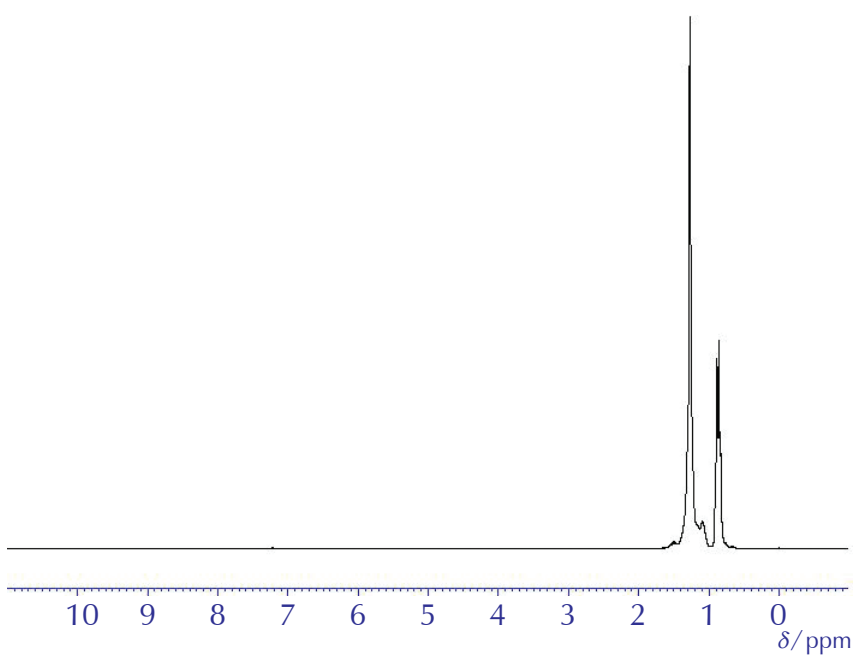

Slika 7 - Tipični spektar ${ }^{1} \mathrm{H}$ NMR biljnog ulja tretiranog vodikom Fig. 7 - Typical ${ }^{1}$ H NMR spectrum of hydrotreated vegetable oils

\section{Zaključak}

U ovom preglednom radu opisane su mogućnosti primjene spektroskopije NMR u analizi biodizelskog goriva. Poznavanje sastava biodizelskih i dizelskih goriva važno je za predviđanje kvalitete i ekoloških svojstava krajnjeg komercijalnog proizvoda. Naveden je niz primjera primjene tehnika ${ }^{1} \mathrm{H} \mathrm{i}{ }^{13} \mathrm{C}$ NMR u analizi biodizelskog goriva kojima je pokazano da je spektroskopija NMR vrlo pogodna i učinkovita metoda za njihovu analizu. Pregledom je obuhvaćena i primjena spektroskopije NMR u analizi HVO-a koje pripada biogorivima druge generacije. Budući da su tehnike NMR teorijski i instrumentno u stalnom razvoju, u budućnosti se predviđa njihova još veća primjena u ovome području.

\section{Popis kratica i simbola List of abbreviations and symbols}
ANNs - umjetne neuronske mreže
- artificial neural networks
FAME - metilni esteri masnih kiselina
- fatty acid methyl ester
gHSQC - heteronuklearna korelacijska spektroskopija NMR koja se koristi koherencijom od jednog kvanta uz primjenu gradijenata magnetskog polja
- gradient Heteronuclear Single Quantum Coherence
HVO - biljna ulja tretirana vodikom
- hydrotreated vegetable oils
MLR - višestruka linearna regresija
- multiple linear regression
NMR - nuklearna magnetska rezonancija
- nuclear magnetic resonance
UV-VIS - ultraljubičasto i vidljivo
- ultraviolet-visible
PCA - analiza glavnih komponenata
- principal component analysis

PLSR - metoda najmanjih kvadrata

- partial least squares regression

A $\quad-$ množinski udjel strukturne skupine masnih kiselina u ukupnim masnim kiselinama

- amount fraction of fatty acid structure type in total fatty acids

I - - integral signala protona u spektroskopiji NMR

- integral of proton NMR peak

\section{Literatura \\ References}

1. D. Sinčić, Kemijsko-inženjerski aspekti proizvodnje biodizela. I. Biogoriva, svojstva biodizela i osnove proizvodne tehnologije, Kem. Ind. 63 (2014) 19-31.

2. M. R. Monteiro, A. R. P. Ambrozin, L. M. Liao, A. G. Ferreira, Determination of biodiesel blend levels in different diesel samples by ${ }^{1} \mathrm{H}$ NMR, Fuel 88 (2009) 691-696, doi: http:// dx.doi.org/10.1016/j.fuel.2008.10.010.

3. G. Knothe, Some aspects of biodiesel oxidative stability, Fuel Proces. Teh. 88 (2007) 669-677, doi: http://dx.doi. org/10.1016/j.fuproc.2007.01.005.

4. E. Stauffer, D. Byron, Alternative fuels in fire debris analysis: Biodiesel basics, J. Forensic. Sci. 52 (2007) 371-379, doi: http://dx.doi.org/10.1111/j.1556-4029.2006.00380.x.

5. E. C. Zuelta, L. Baena, L. A. Rios, J. A. Calderon, The oxidative stability of biodiesel and its impact on the deterioration of metallic and polymeric materials: A Review, J. Braz. Chem. Soc. 23 (2012) 2159-2175, doi: http://dx.doi.org/10.1590/ S0103-50532012001200004.

6. G. Gelbard, O. Bres, R. M. Vargas, F. Vielfaure, U. F. Schuchardt, ${ }^{1} \mathrm{H}$ nuclear magnetic resonance determination of the yield of the transesterification of rapeseed oil with methanol, J. Am. Oil Chem. Soc. 72 (1995) 1239-1241, doi: http://dx.doi.org/10.1007/BF02540998.

7. G. Knothe, Monitoring a progress transesterification reaction by fiber-optic near infrared spectroscopy with correlation to ${ }^{1} \mathrm{H}$ nuclear magnetic resonance spectroscopy, J. Am. Oil Chem. Soc. 77 (2000) 489-493, doi: http://dx.doi. org/10.1007/s11746-000-0078-5.

8. M. Morgestern, J. Cline, S. Meyer, S. Cataldo, Determination of the kinetics of biodiesel production using proton nuclear magnetic resonance spectroscopy ( ${ }^{1} \mathrm{H}$ NMR), Energy Fuels 20 (2006) 1350-1353, doi: http://dx.doi.org/10.1021/ ef0503764.

9. G. Rafael, D. Defferrari, Q. B. Reiznautt, I. R. Cadore, D. Samios, Transesterification double step process modification for ethyl ester biodiesel production from vegetable and waste oils, Fuel 92 (2012) 197-203, doi: http://dx.doi. org/10.1016/j.fuel.2011.08.010.

10. J. K. Satyarthi, D. Srinivas, P. Ratnasamy, Estimation of free fatty acid content in oils, fats, and biodiesel by $1 \mathrm{H}-\mathrm{NMR}$ spectroscopy, Energy Fuels 23 (2009) 2273-2277, doi: http://dx.doi.org/10.1021/ef801011v.

11. G. Knote, J. A. Kenar, Determination of the fatty acid profile by ${ }^{1}$ H NMR spectroscopy, Eur. J. Lipid. Sci. Tehnol. 106 (2004) 88-96, doi: http://dx.doi.org/10.1002/ejlt.200300880.

12. Y. Miyake, K. Yokomizo, N. Matsuzaki, Determination of unsaturated fatty acid composition by high-resolution nuclear magnetic resonance spectroscopy, J. Am. Oil Chem. Soc. 75 (1998) 1091-1094, doi: http://dx.doi.org/10.1007/s11746998-0118-4.

13. N. Kapilan, R. Reddy, Evaluation of methyl esters of Mahua 
Pil (Madhuca Indica) as diesel fuel, J. Am. Oil Chem. Soc. 85 (2008) 185-188, doi: http://dx.doi.org/10.1007/s11746007-1179-5.

14. A. Casas, M. J. Ramos, A. Perez, A. Simon, C. Lucas-Torres, A. Moreno, Rapid quantitative determination by ${ }^{13} \mathrm{C} N \mathrm{NMR}$ of the composition of acetylglycerol mixtures as byproduct in biodiesel synthesis, Fuel 92 (2012) 180-186, doi: http:// dx.doi.org/10.1016/j.fuel.2011.06.061.

15. G. Knote, Analysis of oxidized biodiesel by ${ }^{1} \mathrm{H}-\mathrm{NMR}$ spectroscopy and effect of contact area with air, Eur. J. Lipid Sci. Technol. 108 (2006) 493-500, doi: http://dx.doi. org/10.1002/ejlt.200500345.

16. D. J. Cookson, B. E. Smith, Determination of carbon C, $\mathrm{CH}, \mathrm{CH} 2$ and $\mathrm{CH} 3$ group abundances in liquids derived from petroleum and coal using selected multiplet ${ }^{13} \mathrm{C} N M R$ spectroscopy, Fuel 62 (1983) 34-38, doi: http://dx.doi. org/10.1016/0016-2361(83)90248-X.

17. D. J. Cookson, B. E. Smith, Determination of structural characteristics of saturates from diesels and kerosene fuels by carbon-13 nuclear magnetic resonance spectrometry, Anal. Chem. 57 (1985) 864-871, doi: http://dx.doi.org/10.1021/ ac00281a020.

18. J. M. Dereppe, C. Moreux, Measurement of $\mathrm{CHn}$ group abundances in fossil fuel materials using DEPT ${ }^{13} \mathrm{C}$ NMR , Fuel 64 (1985) 1174-1176, doi: http://dx.doi.org/10.1016/00162361(85)90127-9.

19. L. Griffiths, Annual Reports on NMR Spectroscopy, Automatic Analysis of NMR Spectra, Elsevier Inc. 50 (2003) 217-251.

20. R. Meusinger, R. Moros, Determination of octane numbers of gasoline compounds from their chemical structure by ${ }^{13} \mathrm{C}$ NMR spectroscopy and neural networks, Fuel $\mathbf{8 0}$ (2001) 613-621, doi: http://dx.doi.org/10.1016/S00162361(00)00125-3.

21. IP 499/03 Standard Methods for Analysis and Testing of Petroleum and Related Products and British Standard 2000 parts, Methods IP 361 to 501, The Institute of Petroleum London, 2003, 499.1-499.4.

22. J. Parlov Vuković, S. Telen, V. Srića, P. Novak, The use of ${ }^{13} \mathrm{C}$ NMR spectroscopy and comprehensive two-dimensional gas chromatography, GCxGC, for identification of compounds involved in diesel fuel oxidative behaviour, Croat. Chem. Acta 84 (2011) 537-541, doi: http://dx.doi.org/10.5562/ cca1874.

23. R. Zamora, G. Gomez, F. J. Hidalgo, Classification of vegetable oils by high resolution ${ }^{13} \mathrm{C}$ NMR spectroscopy using chromatographically obtained oil fractions, J. Am. Oil Chem. Soc. 79 (2002) 267-272, doi: http://dx.doi.org/10.1007/ s11746-002-0472-z.

24. Y. Miyake, K. Yokomizo, N. Matsuzaki, Determination of unsaturated fatty acid composition by high-resolution nuclear magnetic resonance spectroscopy, J. Am. Oil Chem. Soc. 75 (1998) 1091-1094, doi: http://dx.doi.org/10.1007/s11746998-0118-4.

25. M. O. Farrus, G. Villorbina, J. Eras, F. Gatius, M. Torres, R. Canela, Determination of the iodine value of biodiesel using ${ }^{1} \mathrm{H}$ NMR with 1,4-dioxane as an internal standard, Fuel 89 (2010) 3489-3492, doi: http://dx.doi.org/10.1016/j. fuel.2010.06.016.

26. S. Y. Rada, B. Costa, R. J. S. Freitas, Determination of iodine value in ethylic biodiesel samples by ${ }^{1} \mathrm{H}-\mathrm{NMR}$, Ann. Magn. Reson. 6 (2007) 69-75.

27. T. Igarashi, M. Aursand, Y. Hirata, I. S. Gribbestad, S. Wada, M. Nonaka, Nondestructive quantitative determination of docosahexaenoic acid and n-3 fatty acids in fish oils by high-resolution ${ }^{1} \mathrm{H}$ nuclear magnetic resonance spectrosco- py, J. Am. Oil Chem. Soc. 75 (2000) 737-748, doi: http:// dx.doi.org/10.1007/s11746-000-0119-0.

28. D. V. Nadai, J. B. Simoes, C. E. N.Gatts, P. C. M.L. Miranda, Inference of the biodiesel cetane number by multivariant techniques, Fuel 105 (2013) 325-330, doi: http://dx.doi. org/10.1016/j.fuel.2012.06.018.

29. G. S. Kapur, A. Ecker, R. Meusinger, Establishing quantitative structure - property relationships (QSPR) of diesel samples by proton - NMR \& Multiple Linear Regression (MLR) Analysis, Energy \& Fuels 15 (2001) 943-948, doi: http://dx.doi. org/10.1021/ef010021u.

30. J. Mühl, V. Srića, Determination of fluid catalytic cracking gasoline octane number by NMR spectrometry, Fuel $\mathbf{6 6}$ (1987) 1146-1149, doi: http://dx.doi.org/10.1016/00162361(87)90314-0.

31. J. Mühl, V. Srića, M. Jednačak, Determination of coking gasoline octane number by NMR spectrometry, Fuel $\mathbf{7 2}$ (1993) 987-989, doi: http://dx.doi.org/10.1016/00162361(93)90297-F.

32. D. J. Cookson, P. Iliopoulos, B. E. Smith, Composition-property relations for jet and diesel fuels of variable boiling range, Fuel 74 (1995) 70-78, doi: http://dx.doi.org/10.1016/00162361(94)P4333-W

33. I. S. Flores, M. S. Godinho, A. E. de Oliveira, G. B. Alcantara, M. R. Monteiro, S. M. C. Menezes, L. M. Liao, Discrimination of biodiesel blends with ${ }^{1} \mathrm{H}$ NMR spectroscopy and principal component analysis, Fuel 99 (2012) 40-44, doi: http:// dx.doi.org/10.1016/j.fuel.2012.04.025.

34. N. A. Chira, M. C. Todasca, A. Nicolescu, A. Rosu, M. Nicolae, S. I. Rosca, Evaluation of the computational methods for determining vegetable oils composition using ${ }^{1} \mathrm{H}$ - NMR spectroscopy, Rev. Chim. (Bucharest) 62 (2011) 42-46.

35. B. Basu, G. S. Kapur, A. S. Sapral, R. Meusinger, A neural network approach to the prediction of cetane number of diesel fuels using nuclear magnetic resonance (NMR) spectroscopy, Energy \& Fuels 17 (2003) 1570-1575, doi: http://dx.doi. org/10.1021/ef030083f.

36. J. Mühl, V. Srića, B. Mimica, M. Tomašković, Characterization of middle petroleum fraction by nuclear magnetic resonance spectrometry, Anal. Chem. 54 (1982) 1871-1874, doi: http://dx.doi.org/10.1021/ac00248a049.

37. B. Klofutar, J. Golub, Microorganisms in diesel and in biodiesel fuels, Acta Chim. Slov. 54 (2007) 744-748.

38. Z. Janović, Polimerizacije i polimeri, Hrvatsko društvo kemijskih inženjera i tehnologa, Zagreb, 1992.

39. V. Srića, J. Mühl, B. Metelko, Određivanje strukture polietilena niske gustoće ${ }^{13} \mathrm{C}$ NMR spektrometrijom, Polimeri $\mathbf{1 0}$ (1989) 153-156.

40. R. Vuković, V. Kurešević, V. Srića, D. Fleš, F. Ranogajec, Copolymerization of 2-vinylnaphthalene with benzylidenemalononitrile, J. Macromol. Sci. - Pure Appl. Chem. 31 (1994) 20012010, doi: http://dx.doi.org/10.1080/10601329409350114.

41. A. Erceg, R. Vuković, G. Bogdanić, V. Srića, D. Fleš, Copolymerization of n-acryl-n,n-dicyclohexylurea with styrene, J. Macromol. Sci. - Pure Appl. Chem. 38 (2001) 839-850, doi: http://dx.doi.org/10.1081/MA-100104451.

42. A. Erceg Kuzmić, V. Srića, G. Bogdanić, R. Vuković, D. Fleš, Polimerizacija, toplinska stabilnost i mehanizam razgradnje kopolimera (met)akril-dicikloheksiloheksiluree i (met) akril-diizopropiluree sa stirenom i $\alpha$-metilstirenom, Kem. Ind. 55 (2006) 213-221.

43. A. Erceg Kuzmić, M. Radošević, V. Srića, R. Vuković, Studies on the influence of long chain acrylic esters polymers with polar monomers as crude oil flow improver additives, 
Fuel 87 (2008) 2943-2950, doi: http://dx.doi.org/10.1016/j. fuel.2008.04.006

44. I. Šoljić Jerbić, J. Parlov Vuković, A. Jukić, Procesi dobivanja disperznih polimetakrilatnih aditiva u mineralnom baznom ulju, VIII. Susret mladih kemijskih inženjera 2010., Fakultet kemijskog inženjerstva i tehnologije Sveučilišta u Zagrebu, Knjiga sažetaka (2010) 149-149.

45. J. Parlov Vuković, V. Srića, P. Novak, Primjena spektroskopije NMR $u$ analizi naftnih derivata i proizvoda, Kem. Ind. 61
(2012) 513-522.

46. I. Šoljić Jerbić, J. Parlov Vuković, A. Jukić, Production and Application Properties of Dispersive Viscosity Index Improvers, Ind. Eng. Chem. Res. 51 (2012) 11914-11923, doi: http:// dx.doi.org/10.1021/ie301010n.

47. S. Bezergianni, A. Kalogianni, I. A. Vasalos, Hydrocracking of vacuum gas oil-vegetable oil mixtures for biofuels production, Bioresource Technology 100 (2009) 3036-3042, doi: http://dx.doi.org/10.1016/j.biortech.2009.01.018.

\section{SUMMARY \\ Application of NMR Spectroscopy in the Analysis of Biodiesel \\ Jelena Parlov Vuković}

In this review, the most important and most frequently used one and two dimensional NMR techniques for biodiesel analysis have been described. Biodiesel is an ecologically accepted alternative fuel consisting of saturated and non-saturated methyl esters of fatty acids. Owing to the fact that analysis of biodiesel chemical composition and properties pose a challenge to analytical chemists, novel and more efficient analytical techniques and methods are being developed constantly. In that respect, NMR spectroscopy is an excellent method, which can provide a wealth of information on the composition and structural properties of biodiesel. NMR can be used for determination of the iodine value of biodiesel, fatty acid profile, and percentage of fatty acid methyl esters. Furthermore, NMR spectral analysis can give valuable data on raw materials used for biodiesel production and the process of trans-esterification can be monitored. By the application of ${ }^{1} \mathrm{H}$ and ${ }^{13} \mathrm{C}$ NMR techniques, the composition and structure of additives for preventing the growth of microorganisms can be determined. For that purpose, apart from ${ }^{1} \mathrm{H}$ and ${ }^{13} \mathrm{C}$ spectra, ${ }^{31} \mathrm{P}$ spectra are used as well. Also, composition of acetylglycerol mixtures and corresponding by-products of biodiesel synthesis can be analysed. NMR spectroscopy has proven useful in analysis of hydrotreated vegetable oils, which have better fuel properties than biodiesel produced via transesterification and their application improves engine fuel economy. In this paper, representative NMR spectra of diesel, biodiesel and hydrotreated vegetable oil and those of biocide samples recorded in the Laboratory for NMR spectroscopy of INA d. d. are given. The advantages of using NMR spectroscopy in biodiesel analysis and determination of its properties are discussed.

\section{Key words}

NMR spectroscopy, biodiesel, fatty acid methyl esters, hydrotreated vegetable oils

INA - Industrija nafte d. d.

Refining \& Marketing Business Division

Product Development Department

Central Testing Laboratory

Lovinčićeva 4

10002 Zagreb, Croatia
Review

Received July 29, 2014 Accepted September 24, 2014 